\title{
PRODUTOS EDUCACIONAIS NA ÁREA DE ENSINO DA CAPES: O QUE HÁ ALÉM DA FORMA?
}

Rony Freitas ${ }^{1}$

DOI: https://doi.org/10.36524/profept.v5i2.1229

\begin{abstract}
Resumo
Nos últimos anos a Área de Ensino da CAPES tem avançado na compreensão e na caracterização de Produtos Educacionais, obrigatórios para Mestrados e Doutorados Profissionais. Porém, ainda é preciso refletir sobre a não redução desses produtos a elementos físicos, e compreender que são compostos por uma série de componentes internos que se referem à sua forma de organização, conteúdos e conceitos, organização didática e estrutura condizentes com o contexto para o qual se destinam. No presente artigo é feita uma reflexão teórica, no sentido de indicar novas temáticas para serem debatidas nesse processo de compreensão desses materiais, apontando caminhos, para que se possa avançar na constituição de uma base teórica para elaboração e avaliação de Produtos Educacionais. As reflexões feitas apontam não somente para uma nova forma de conceber os produtos, mas também para novas mudanças estruturais no que diz respeito às formas que escolhemos para informar os seus elementos constituintes a partir de três eixos: conceitual, pedagógico e comunicacional.
\end{abstract}

Palavras-chave: Produto Educacional; Área de Ensino; Programas de Pós-Graduação Profissionais.

\section{EDUCATIONAL PRODUCTS IN THE CAPES EDUCATION/TEACHING AREA: WHAT IS THERE BEYOND THE PRESENTATION WAY?}

\begin{abstract}
In the last few years, the CAPES Education/Teaching Area has advanced in the understanding and characterization of Educational Products, mandatory for professionals Master and Doctorate. However, a point that still requires further reflection is the understanding that such products cannot be reduced to a physical element, whether printed or virtual, but that it is composed of a series of internal components that refer to the symbolic systems mobilized, their organization way, with contents and concepts to be learned, with didactic organization and structure consistent with the context for which it is intended. In this text, a theoretical reflection is made, based on lived experiences, trying to point out new themes to be debated in this process of identity construction, pointing out some possible paths so that we can advance more and more in the constitution of a solid theoretical basis for elaboration and evaluation of Educational Products. The reflections made point not only to a new way of conceiving products, but also to new structural changes with regard to the ways we choose to inform its various elements, having three constituent axes: conceptual, pedagogical and communicational.
\end{abstract}

Keywords: Educational Product; Educational/Teaching Area; Professional post Graduate Programs.

\footnotetext{
${ }^{1}$ Instituto Federal do Espírito Santo; E-mail: freitasrco@ gmail.com
} 


\section{INTRODUÇÃO}

Nos últimos anos a Área de Ensino da Coordenação de Aperfeiçoamento de Pessoal de Nível Superior - CAPES tem avançado na compreensão e na caracterização de Produtos Educacionais, obrigatórios para Mestrados e Doutorados Profissionais, mobilizando esforços de muitos pesquisadores para definir melhores critérios para sua inserção nos processos de pesquisa, aplicação, validação, registros, divulgação e diálogos com contextos educacionais formais e não formais. Porém, embora se reconheça que já houve grandes avanços nessa compreensão, precisamos continuar os debates para irmos adiante, buscando aprimorar critérios que possam cada vez mais ajudar a elaborar recursos e processos pedagógicos que possam contribuir para melhorias em processos de ensino e de aprendizagem.

Um ponto importante que demanda maiores reflexões é justamente a compreensão de que o Produto Educacional não pode ser reduzido a um elemento físico, seja ele impresso ou virtual, mas que é composto por uma série de componentes internos que se referem aos sistemas simbólicos mobilizados, sua forma de organização, com conteúdos e conceitos a serem aprendidos, com organização didática e estrutura condizentes com o contexto para o qual se destina. Essa discussão ganha relevância nesse momento em que os Doutorados Profissionais já são uma realidade e que será necessário pensar em remodelação e ampliação do que já foi feito até aqui.

A Área de Ensino da CAPES é caracterizada por ser essencialmente de pesquisa translacional, o que significa, nesse caso específico, que há uma intenção de que os conhecimentos produzidos sejam aplicados, com possibilidades de replicação, em contextos reais por meio de produtos e processos educativos (BRASIL, 2019). Essa ênfase na aplicação é reforçada, sendo uma exigência para pesquisas inseridas em programas profissionais que têm como elemento central o desenvolvimento de

[...] um processo ou produto educativo aplicado em condições reais de sala de aula ou outros espaços de ensino, em formato artesanal ou em protótipo. Esse produto pode ser, por exemplo, uma sequência didática, um aplicativo computacional, um jogo, um vídeo, um conjunto de vídeo-aulas, um equipamento, uma exposição, entre outros. A dissertação/tese deve ser uma reflexão sobre a elaboração e aplicação do produto educacional respaldado no referencial teórico metodológico escolhido (BRASIL, 2019a, p. 15).

Porém, alguns questionamentos precisam ser feitos sobre essa posição. Será que é suficiente dizer que o produto educacional é uma sequência didática, um aplicativo 
computacional, um jogo, um vídeo etc.? Será que descrevê-lo dessa maneira não implica em valorizar mais a forma que o conteúdo? Não seria mais adequado descrever o produto levandose em consideração conteúdos abordados e métodos de ensino utilizados/indicados? Em alguns casos, não está havendo uma confusão entre a forma como o produto é apresentado para a sociedade e o que realmente o configura?

Sem a intenção de apontar respostas a todas essas questões, mas na expectativa de contribuir para o debate, trago nesse artigo algumas reflexões a fim de apontar alguns possíveis caminhos para que possamos avançar cada vez mais na constituição de uma base teórica para elaboração e avaliação de Produtos Educacionais de Mestrados e Doutorados Profissionais da Área de Ensino da CAPES.

\section{O QUE A ÁREA DE ENSINO INDICA}

Seguindo uma tradição já consolidada, a estratégia de escuta e plenárias realizadas a cada Seminário de Acompanhamento, realizado pela Área de Ensino, têm garantido um processo cada vez mais transparente e democrático de discussão (RIZZATTI et al, 2020). Segundo os mesmos autores, esses espaços têm apontado o Produto Educacional como a principal produção de Mestrados e Doutorados Profissionais. No Seminário de Meio Termo realizado pela Área de Ensino no ano de 2019 foi dado um passo importante no que diz respeito à avaliação de produtos educacionais, evidentemente vinculada a uma reflexão sobre seus processos de desenvolvimento e validação.

Na Avaliação Quadrienal 2013-2016 a Área já havia criado, de forma bastante inovadora, um Sistema Qualis-Educacional, semelhante ao que já havia para Revistas. Tal sistema foi implementado e os produtos foram avaliados tendo essa referência, utilizando como critérios, além do vínculo à pesquisa do mestrando e da existência de URL própria,

(i) validação (comitê ad hoc, por órgão de fomento ou por banca de dissertação); (ii) registro em sistema de informações em âmbito nacional ou internacional (ISBN, ISSN, ANCINE, Registro de Domínio, Certificado de Registro Autoral, registro ou averbação na Biblioteca Nacional, registros de patentes e marcas submetidos ao INPI). O registro se concretiza com vinculo aos repositórios em Instituições Nacionais, Internacionais, Universidades, ou domínios do governo na esfera local, regional ou federal (Portal do Professor, Banco Internacional de Objetos Educacionais, Vérsila Biblioteca Digital, Arca-Fiocruz, RIVED, LabVirt-USP, Multimeios, Escola Digital, Biblioteca Digital de Ciências-Unicamp, ChemCollective-USA, ITSON-México, JORUM-UK, EduCAPES-Brasil); (iii) uso em sistemas educacionais/de saúde (sim ou não em sistema local, municipal, estadual, nacional ou internacional); e (iv) acesso on-line (sem acesso, acesso via rede fechada; 
acesso por Portal nacional ou internacional, Youtube, Vimeo e outros com acesso público e gratuito; acesso público e gratuito pela página do programa; acesso público e gratuito por Repositório institucional - nacional ou internacional). (ARAÚJO-JORGE et al, 2017, p. 9)

Para o quadriênio 2013-2016 foi delegada a um grupo de colaboradores vinculados a programas de pós-graduação da Área de Ensino a tarefa de, a partir desses referenciais, fazer a avaliação de todos os Produtos indicados por todos os programas, que se configurou em um trabalho extremamente desgastante, uma vez que foram avaliados mais de três mil produtos educacionais. Além disso, o Grupo de Trabalho (GT) constituído no Seminário de Meio Termo de 2019 avançou um pouco mais nessa proposta, tendo como ponto de partida o que já havia sido consolidado até então, fruto de muitas discussões, e o documento produzido pelo GT de Produção Técnica delegado pela CAPES (BRASIL, 2019b). Nesse documento é apresentada uma metodologia de avaliação da produção Técnica e Tecnológica, com a proposta de ser aplicável a todas as áreas de avaliação. Como resultado, foram apontados:

1. Aderência (critério obrigatório): $O$ critério aderência se faz obrigatório para a validação de uma produção para o Programa de Pós-Graduação - PPG em avaliação, visto que os produtos deverão apresentar origens nas atividades oriundas das linhas de pesquisas/atuação e projetos vinculados a estas linhas.

2. Impacto: A avaliação deste critério está relacionada com as mudanças causadas pelo produto Técnico e Tecnológico no ambiente em que o mesmo está inserido. Para avaliar tal critério é importante entender o motivo de sua criação, onde a questão do demandante se torna de grande relevância, e também deve estar claro qual o foco de aplicação do produto, permitindo assim avaliar em qual(is) área(s) as mudanças poderão ser percebidas.

3. Aplicabilidade: $\mathrm{O}$ critério aplicabilidade faz referência à facilidade com que se pode empregar o Produto a fim de atingir os objetivos específicos para os quais foi desenvolvida. Entende-se que uma produção que possua uma alta aplicabilidade, apresentará uma abrangência elevada, ou que poderá ser potencialmente elevada, incluindo possibilidades de replicabilidade como produção técnica.

4. Inovação: O conceito de inovação é muito amplo, mas em linhas gerais, pode-se definir como a ação ou ato de inovar, podendo ser uma modificação de algo já existente ou a criação de algo novo.

5. Complexidade: Pode ser entendida como uma propriedade associada à diversidade de atores, relações e conhecimentos necessários à elaboração e ao desenvolvimento de produtos técnico-tecnológicos. (BRASIL, 2019b, p. 2225 , grifos nossos)

O Grupo de Trabalho apontou, de forma coerente, que diferentemente do que foi feito na quadrienal 2013-2016, a banca de avaliação da dissertação seria a instância mais apropriada para fazer uma avaliação qualitativa do Produto Educacional. Rizzatti et al (2020) afirmam que, 
embora essa já seja uma prática adotada por alguns programas da Área, essa forma de avaliação ajudará a corrigir uma falha em processos de avaliação dos produtos, uma vez que, segundo os autores, ao longo dos anos as bancas de defesa têm focado excessivamente na avaliação da dissertação, avaliando pouco (ou nada) o Produto Educacional. Assim, a partir das premissas postas, propôs-se uma ficha que, de forma bem próxima ao proposto pelo GT de Produção Técnica da CAPES, avaliasse os seguintes eixos:

- Complexidade: Compreende-se como uma propriedade do Produto/ Processo Educacional - PE relacionada às etapas de elaboração, desenvolvimento e/ou validação do Produto Educacional. Aqui é avaliada a relação do PE com a questão de pesquisa, a forma de aplicação e análise com base nos referenciais teóricos e teórico-metodológicos empregados. Esse item da ficha é o mais próximo de uma avaliação mais qualitativa do PE, embora o peso da análise incida sobre o que está escrito na dissertação/tese e não no produto em si.

- Impacto: Considera-se a forma como o PE foi utilizado e/ou aplicado nos sistemas educacionais, culturais, de saúde ou CT\&I (Ciência, Tecnologia e Inovação). É importante destacar se a demanda foi espontânea ou não.

- Aplicabilidade: Relaciona-se ao potencial de facilidade de acesso e compartilhamento que o produto educacional possui, para que seja acessado e utilizado de forma integral e/ou parcial em diferentes sistemas. Deve-se analisar a aplicação ou aplicabilidade do PE.

- Acesso: Relaciona-se à forma de acesso ao PE, analisando-se de possui e qual tipo de acesso.

- Aderência: Compreende-se que PE deve ter origens nas atividades oriundas das linhas e projetos de pesquisa do PPG.

- Inovação: Considera-se que o PE é/foi criado a partir de algo novo ou da reflexão e modificação de algo já existente revisitado de forma inovadora e original (RIZZATTI et al, 2020).

Embora a proposta de avaliação apresente avanços, é perceptível a carência de itens que apontem para uma avaliação sobre conteúdos e metodologias adotadas na elaboração do PE, seja a forma como são abordados ou dos referenciais teóricos que subsidiaram as escolhas. A maioria dos itens avaliados são de caráter relativamente técnico, demandando observações do tipo cumprido ou não cumprido, levando-se pouco em consideração os possíveis impactos em 
termos formativos sobre o espaço educacional para o qual ele se destina. Ficam, portanto, as seguintes questões: 1) não seria esperado que a banca fizesse uma avaliação mais qualitativa?; 2) tendo em vista que o produto tem como finalidade uma inserção qualitativa nos processos educacionais, não seria importante avaliar se está ancorado em metodologias de ensino atuais?; 3) não seria o caso da banca se preocupar também com os aspectos conceituais do produto, levando em conta a coerência com discussões que devem ser feitas na dissertação ou na tese?; 4) a forma escolhida para se comunicar com o público-alvo não deveria ser avaliada? Mais uma vez, não se trata aqui nesse artigo de responder tais questões, são apenas provocadoras para reflexões, alguma feitas aqui e outras a serem objetos de debates que ainda deverão ser feitos.

\section{O PRODUTO EDUCACIONAL PARA ALÉM DA FORMA}

No segundo semestre de 2020, estudantes da Área de Concentração em Educação Matemática de um Mestrado Profissional da Área de Ensino, cursaram uma disciplina denominada Análise e Produção de Recursos Didáticos, que tem como meta principal refletir sobre possibilidades de elaboração dos Produtos Educacionais. Uma das tarefas dessa disciplina propunha aos mestrandos, iniciando o segundo semestre do curso, que fizessem uma pequena descrição de seus produtos, ainda que fosse uma ideia preliminar. A Figura 1 traz algumas dessas descrições.

Como pode ser visto, todos indicam o produto pela sua forma, sejam elas Guias Didáticos, Livros, Catálogos, Caderno de Atividades, Curso em Ambiente Virtual de Aprendizagem. Mas, uma reflexão precisa ser feita. Se a Área de Ensino (BRASIL, 2019a) aponta que o produto educativo deve ser aplicado ou aplicável em condições reais de sala de aula ou outros espaços de ensino e ainda que a dissertação/tese deve ser uma reflexão sobre a elaboração e aplicação desse produto, tem sentido caracterizar o produto simplesmente pela sua forma de apresentação? Será que realmente é o guia didático, por exemplo, que passou por esse processo de reflexão presente na dissertação/tese ou ele é simplesmente uma forma de materializar o que realmente compõe o produto? Não seria pertinente caracterizar o produto pelo que ele contém e pela forma que ele se direciona ao público-alvo? Não seria o caso de diferenciar o produto em si da forma escolhida para materializá-lo e divulgá-lo?

Para continuar essa discussão, é importante dizer sobre a complexidade que é abordar de forma homogênea bases que possam sustentar teoricamente desenvolvimento e a avaliação de toda a diversidade de produtos educacionais produzidos pelos diversos programas 
vinculados à Área de Ensino, especialmente aqueles voltados para os espaços de educação não formal em que o público-alvo é bastante heterogêneo. Muito embora a própria Área entenda que a vocação das pesquisas de processos e produtos educacionais seja voltada, especialmente, para Educação Básica, Ensino Superior, Ensino em Saúde e tecnologias (BRASIL, 2019a), há uma crescente produção voltada para outros espaços. Um exemplo ocorre no âmbito do Mestrado Profissional em Educação Profissional e Tecnológica ofertado em Rede Nacional, que tem produzido, em grande quantidade pelas 40 instituições que o compõem, produtos destinados ao ensino em contextos profissionais diversos.

Figura 1: Propostas preliminares de Produtos Educacionais de mestrandos iniciantes

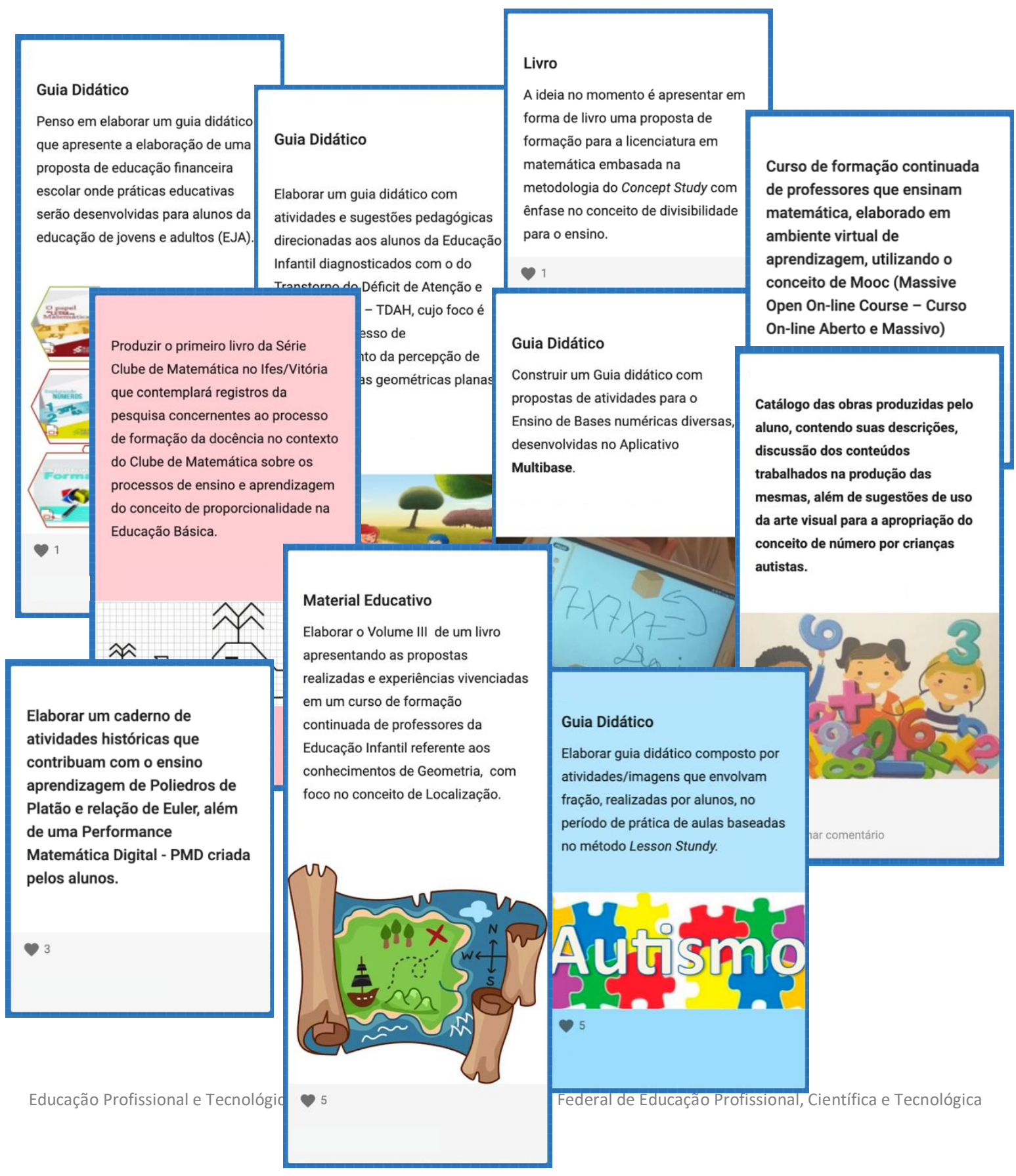


Mas, em termos da concepção e das bases conceituais que os sustentam, há de se encontrar elementos que possam constituir uma identidade de Produtos Educacionais, para além de uma avaliação mais técnica sobre sua forma de origem e apresentação, um olhar para que possamos ampliar essa compreensão de produto educacional que hoje é entendido simplesmente como

[...] o resultado de um processo criativo gerado a partir de uma atividade de pesquisa, com vistas a responder a uma pergunta ou a um problema ou, ainda, a uma necessidade concreta associados ao campo de prática profissional, podendo ser um artefato real ou virtual, ou ainda, um processo. Pode ser produzido de modo individual (discente ou docente) ou coletivo. A apresentação de descrição e de especificações técnicas contribui para que o produto ou processo possa ser compartilhável ou registrado. (BRASIL, 2019a, p. 16)

Comecemos então por buscar esses elementos que aproximam os produtos, independentemente de sua finalidade ou forma de apresentação. Inicialmente, adapto de Gimeno Sacristán (2001) a definição que ele utilizada para materiais escolares para ousar definir Produto Educacional como qualquer instrumento ou objeto que possa servir como recurso para que, mediante sua manipulação, observação ou leitura se oferecem oportunidades para aprender algo, ou seu uso interfere no desenvolvimento de alguma função de ensino. Complementarmente, agora utilizando as ideias de Pagán (1995), os Produtos Educacionais ainda podem ser entendidos como todos aqueles instrumentos e meios que fornecem critérios para colaborar para tomadas de decisão tanto no planejamento quanto na intervenção direta no processo de ensino.

Pagán (1995) faz uma reflexão sobre a importância de se levar em consideração que nenhum produto é um fim em si mesmo, por isso é importante que não somente materialize uma sequência de atividades, ou um vídeo, ou ainda um software, mas, que traga consigo, a proposta de ensino que está subjacente ao que se apresenta de forma explícita no produto. Dessa forma, ainda utilizando as ideias do autor, é importante reconhecer duas formas de caracterizar um Produto Educacional, porém distintas: 1) a sua função didática, ou seja, sua finalidade de 
aprendizagem e metodologias utilizadas para atingir esse fim; 2) o conjunto de meios, recursos ou instrumentos utilizados para materializá-lo.

Pagán (1995), citando Santos Guerra (1991), afirma, que, nesse sentido, os chamados meios audiovisuais e as chamadas novas tecnologias não possuem em si uma capacidade didática inexorável. Ou seja, mais uma vez reforça a ideia de que explicitar o Produto Educacional apenas pela sua forma é limitador para o que se deseja para desenvolvimento das produções realizadas nos programas. Precisamos pensar no Produto Educacional como um objeto que facilita uma experiência de aprendizagem, ou seja, uma experiência de mudança e enriquecimento em algum sentido: conceitual ou perceptivo, afetivo, de habilidades ou atitudes, etc. (KAPLÚN, 2002), e que isso passe cada vez mais a caracterizar de forma explícita o produto, sem necessariamente abrir mão da forma.

O pesquisador espanhol Manuel Area Moreira afirma que todo recurso didático possui três dimensões: semântica, pragmática e sintática (AREA MOREIRA, 2010). A dimensão semântica refere-se a seus conteúdos, informações e mensagens, o que o pesquisador resume como "o que o material diz". A dimensão pragmática se refere ao uso do material, "como e para que será usado". A dimensão sintática se refere aos sistemas simbólicos utilizados no material utilizados para apresentar as informações, "como a mensagem é apresentada".

Essas dimensões, de certa maneira, podem ser aproximadas do que Kaplún $(2002,2003)$ classificou como três eixos para análise e construção de mensagens educativas: eixo conceitual, eixo pedagógico e eixo comunicacional. O eixo conceitual está relacionado ao(s) objeto(s) de conhecimento, foco central do material. $\mathrm{O}$ autor indica que, para definir os elementos que compõem esse eixo, dois tipos de pesquisas prévias são requeridos, uma temática e uma diagnóstica. A pesquisa temática seria para compreender os assuntos e conteúdos abordados e, principalmente, os conceitos que articulam os debates em torno deles, o que requer, evidentemente, um aprofundamento em teorias que sustentem tais conceitos. Essa compreensão é que vai ajudar a selecionar as ideias centrais que serão abordadas pelo material. A pesquisa diagnóstica é importante para conhecer os sujeitos e o meio para o qual o material se destina, especialmente saber quais são suas verdadeiras necessidades a partir do que sabem, o que querem, o que pensam, o que imaginam, o que ignoram sobre o assunto abordado.

O eixo pedagógico, para Kaplún $(2002,2003)$ está relacionado à metodologia de ensino escolhida para o material, assim como à forma de organização dos conteúdos e os recursos pedagógicos indicados. Para o pesquisador, o eixo pedagógico deve ser o articulador principal 
de um material didático, pois a forma escolhida para articular os conteúdos é que vai definir um ponto de partida e um ponto de chegada. Apesar disso, não há garantias nem de que o ponto de partida será bem recebido pelo destinatário e muito menos se o que se pretendia na chegada foi alcançado, mas, o autor destaca que considerar esse eixo no processo de produção do material indica pelo menos um caminho a ser seguido.

O eixo comunicacional está relacionado à forma, ou, como dito por Kaplún (2002, 2003), o veículo escolhido para a viagem. Seguindo essa metáfora, o autor afirma que a escolha do veículo precisa ser adequada ao tipo de estrada que queremos seguir a ainda ao que queremos fazer no percurso. Por exemplo, há situações em que desejaremos ir a pé ou de bicicleta do que de carro, seja porque a estrada não permite ou porque simplesmente queremos apreciar melhor a paisagem. No material didático o tipo de estrada poderia ser traduzido pela proposta metodológica de ensino escolhida ou o tipo de conteúdo a ser trabalhado. A paisagem poderia estar relacionada com os sujeitos ou com o espaço para os quais se destinam. Para uma boa comunicação é preciso encontrar a figura retórica ou poética, a metafórica adequada para comunicar o eixo conceitual e o eixo pedagógico,

[...] será preciso inventar histórias, criar personagens, inventar paisagens visuais ou sonoras. Será preciso compor canções, inventar brincadeiras, escrever cartas ou poemas. Será preciso animar-se a romper moldes para que a mensagem educativa não seja, uma vez mais, equivalente a um sermão impresso, ou a uma chatice audiovisual. (KAPLÚN, 2003, p. 54)

Assim, resumidamente, podemos aproximar as ideias de Area Moreira (2010) e Kaplún (2002, 2003), como foco em Produtos Educacionais, da seguinte forma:

Figura 2: Relação entre teorias de Area Moreira e Kaplún

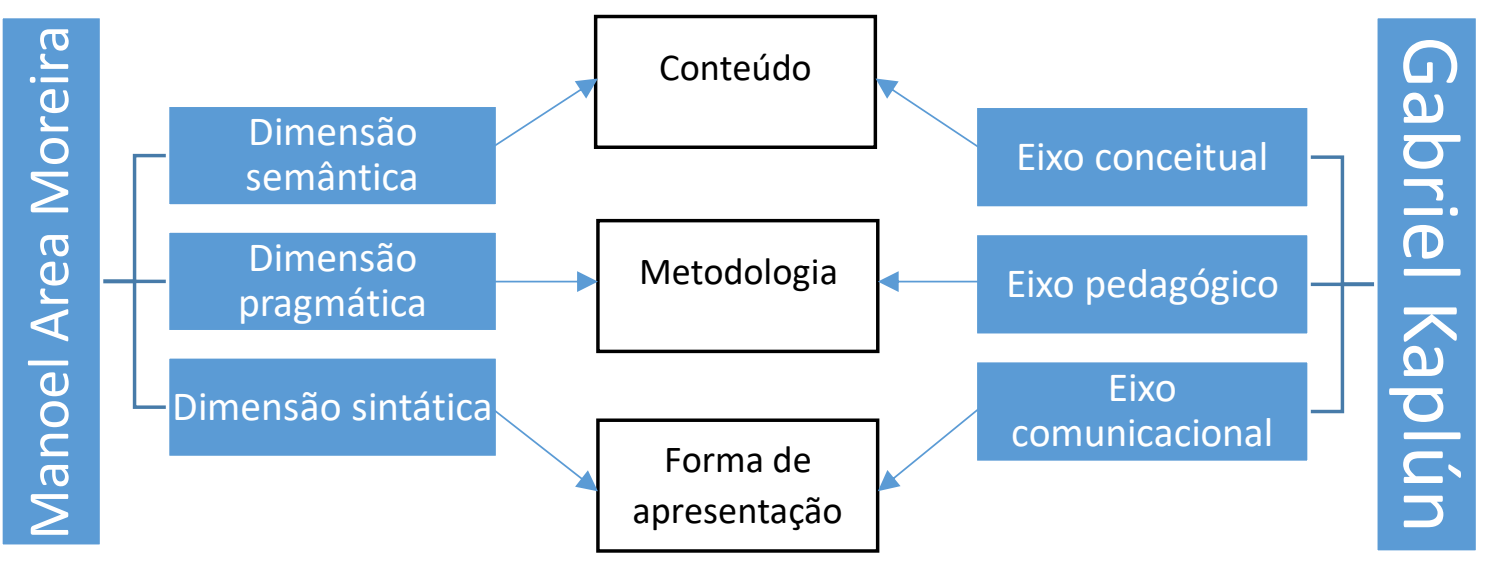


Fonte: Elaborado pelo autor

Rizzatti et al (2020, p. 6), indicam

[...] a necessidade de que as dissertações e teses da modalidade Profissional apresentassem uma seção metodológica para a pesquisa desenvolvida e uma subseção (ou seção específica) destinada a metodologia de desenvolvimento do PE. Assim, as dissertações e teses deverão conter no corpo do texto uma seção ou capítulo, abordando a metodologia de desenvolvimento do PE: 1) contendo a descrição das etapas de delimitação do problema a ser abordado; 2) definições das etapas, idealização e elaboração do PE; 3) prototipagem (quando for o caso); 4) aplicação, avaliação, validação ( $1^{\mathrm{a}}$ instância, mínimo recomendado para o MP), e; 5) análise à luz do referencial teórico e metodológico. Espera-se que os PE resultantes dos MP atinjam plenamente a $1^{\mathrm{a}}$ instância, o que não impede que o mesmo produto tenha a continuidade do desenvolvimento pelo egresso e docente nos grupos de pesquisa dos Programas e que resultariam em produções bibliográficas diversas.

Entendo que há certa confusão entre o que se trata especificamente da elaboração do Produto Educacional e o que se refere ao processo de pesquisa, mesmo que esse processo esteja diretamente relacionada à elaboração. Também é criticável o fato de a análise à luz do referencial teórico não ser exigível para Mestrados Profissionais. Considero que os itens 1, 4 e 5 são etapas contempladas no texto dissertativo, uma vez que têm relação direta com fases da pesquisa. Sendo assim, partir das discussões feitas até aqui, proponho uma remodelação das etapas a serem contempladas na seção destinada à metodologia de desenvolvimento do Produto Educacional, conforme figura a seguir:

Figura 3: Modelo de desenho do Produto Educacional 


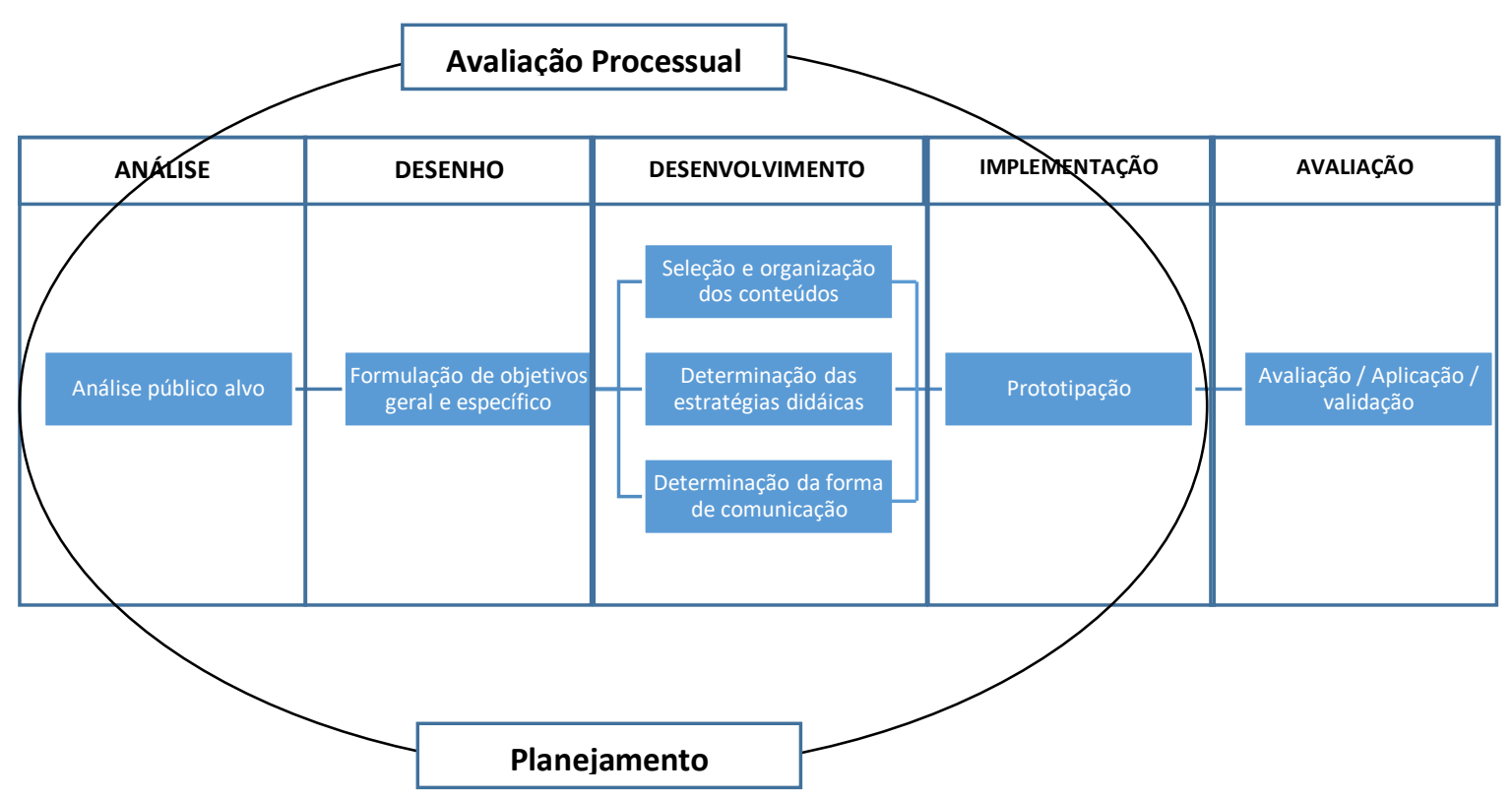

Fonte: Adaptado de Santana (2004, p. 311)

No esquema da figura 3 podem ser distinguidas duas macroetapas, a primeira destacada com uma elipse seria a etapa de planejamento do produto e a outra, isolada, a etapa de avaliação. Seguindo padrão semelhante ao proposto por Rizzatti et al (2020), a primeira seria obrigatória para Mestrados Profissionais, enquanto essa e a última para Doutorados Profissionais. Além disso, a linha elíptica ainda indica que todas essas etapas foram um ciclo contínuo de planejamento a partir de avaliações do processo, o que quer dizer que o protótipo criado ainda não é final, podendo ser melhorado ao longo da pesquisa. Essa forma de ação aponta que, embora o desenho tenha sido feito de forma linear, não necessariamente uma etapa se esgota para iniciar a próxima. Vamos ver a definição de cada uma dessas fases, ainda usando como referência o que foi proposto por Santana (2004):

- Análise: É a base das demais fases do projeto, nesta fase o pesquisador deve identificar as características do público alvo, aqueles para os quais o material se destina. Inicialmente essa análise é preliminar uma vez que muitas vezes o público ainda não é conhecido, por serem necessários contatos prévios. Por isso mesmo a ideia de ser o processo cíclico. 
- Desenho: Nessa etapa o pesquisador define os objetivos de aprendizagem previstos para o Produto Educacional, não se devendo confundir com os objetivos da pesquisa. Tratase aqui das finalidades pedagógicas e a utilidade pedagógica prevista para o produto a ser elaborado.

- Desenvolvimento: Essa etapa contempla discussões já feitas nesse texto, relacionadas às dimensões, propostas por Area Moreira (2010) ou os eixos, conforme Kaplún (2002, 2003). É nesse momento em que bases teóricas que sustentam as escolhas conceituais, a metodologia de ensino e a base comunicacional adotada.

- Implementação: Essa etapa trata do desenvolvimento do protótipo do material, de acordo com o que foi planejado. Essa seria a última etapa obrigatória para Mestrados Profissionais. Caso se encerre aqui, é necessário que o processo de análise seja feito tomando como referência a sua aplicabilidade, à luz dos referenciais teóricos e metodológicos adotados. Essa parte de análise compõe o texto dissertativo.

- Avaliação: Nesse momento o material será colocado em prática com grupos de usuários, sendo que, embora desejável, não seria obrigatória para os Mestrados Profissionais. Trata-se aqui, além da aplicação do material e do processo de análise à luz dos referenciais teóricos e metodológicos adotados. Essa etapa é externa ao produto, tratando-se de parte que compõe o texto dissertativo.

\section{CONSIDERAÇÕES FINAIS}

Muito mais do que ser propositivo, a intenção desse texto é apontar elementos que possam subsidiar a continuidade do diálogo que sempre foi o marco na Área de Ensino da CAPES. A intenção é que as reflexões aqui feitas ajudem a pensarmos em formas de qualificar a elaboração de Produtos Educacionais de modo a ajudar a olharmos para eles como parte fundamental de uma pesquisa científica e não como um simples objeto. Tais reflexões evidentemente apontam para a necessidade de uma avaliação cada vez mais qualitativa, pois somente assim teremos a possibilidade de avançarmos na elaboração de materiais que passem a incorporar o contexto dos diversos espaços educacionais formais ou não formais.

Quando falamos em processos de avaliação de materiais didáticos a partir de uma perspectiva qualitativa é importante nos reportarmos a experiências exitosas feitas anteriormente. Uma dessas experiências tem ocorrido no Brasil, trata-se do Programa Nacional 
de Livros Didáticos que tem feito um trabalho rigoroso de análise de obras que são adquiridas pelo Governo Federal e distribuídas para todas as escolas públicas o país, mesmo merecendo algumas críticas o trabalho realizado após a implementação da Base Nacional Comum Curricular. O Programa, que tem sido desenvolvido desde o ano 1985, tem uma boa parcela de responsabilidade sobre a melhoria da qualidade dos livros didáticos que chegam aos estudantes, isso porque ao longo dos anos foi desenvolvido e aperfeiçoado um rigoroso sistema de avaliação, composto de duas etapas, a primeira técnica na qual há uma verificação de cumprimento de requisitos relacionados à forma de apresentação do livro, feita por uma equipe designada pelo FNDE, e a segunda qualitativa, realizada por consultores oriundos da academia e de sistemas de ensino.

Como resultado desse processo de avaliação, além de uma melhoria progressiva a qualidade dos materiais destinados às escolas públicas brasileiras, mas também as privadas, ao longo dos anos, não se encontram mais nos livros problemas conceituais grosseiros (CARVALHO e LIMA, 2010), por conta de rigorosos processos de avaliação. Tomando-se essa importante ação, bem como as referências aqui aportadas, algumas propostas poderiam ser incorporadas à ficha de avaliação proposta por RIZZATTI et al (2020). Por exemplo, no eixo Complexidade poderia ser perguntado: 1) Eixo conceitual: os conceitos, informações básicas, procedimentos e/ou imagens são apresentados, ou utilizados, sem erro conceitual, indução a erro ou contradições internas e condizentes com o referencial apresentado na dissertação/tese?; 2) Eixo pedagógico: a metodologia de ensino adotada é clara e coerente com o que foi definido na dissertação/tese?; 3) Eixo comunicacional: a linguagem utilizada no produto é adequada ao público alvo a que se destina, quanto ao vocabulário e à clareza na apresentação dos conteúdos e na formulação das instruções?

Para finalizar, creio que um primeiro passo para mudanças em estruturas passa pela forma que escolhemos para comunicar os vários elementos pertencentes a ela. No caso dos Produtos Educacionais, um ponto de partida seria mudarmos uma pergunta que se costuma fazer aos estudantes assim que ingressam em um Mestrado/Doutorado profissional: qual é o produto educacional de sua pesquisa? Talvez essa pergunta deva ser remodelada para algo um pouco mais extenso, algo do tipo: em relação ao seu produto educacional, o que ele abordará, como ele fará essa abordagem, como ele deve ser utilizado e como ele será apresentado/organizado? E, para completar, quais serão os referenciais teóricos que subsidiarão sua elaboração? 


\section{REFERÊNCIAS}

ARAÚJO-JORGE, T. C.; SOVIERZOSKI, H. H.; BORBA, M. C. A área de ensino após a avaliação quadrienal da CAPES: reflexões fora da caixa, inovações e desafios em 2017. Revista Brasileira de Ensino de Ciência e Tecnologia, Ponta Grossa, v. 10, n. 3, p. 1-15, 31 dez. 2017. Universidade Tecnologica Federal do Parana (UTFPR). Diponível em: https://periodicos.utfpr.edu.br/rbect/article/view/7744. Acesso em: 18 jun. 2021.

AREA MOREIRA, M. Los medios de enseñanza: conceptualización y tipología. Web de Tecnología Educativa. Universidad La Laguna, 2010. Disponível em: https://ced.enallt.unam.mx/blogs/socio-pragmatica/files/2013/06/Manuel-Moreira1.pdf. Acesso em: 07 out. 2020.

BRASIL, CAPES. Documento de Área - Ensino. Brasília, 2019a.

BRASIL, CAPES. Grupo de trabalho Produção Técnica. Brasília, 2019 b.

CARVALHO, J. B. P.; LIMA, P. F. Escolha e uso do livro didático. In: CARVALHO, J. B. P. Coleção Explorando o Ensino: Matemática. v. 17. Brasília: MEC, Secretaria de Educação Básica, 2010.

GIMENO SACRISTÁN, J. Los materiales y las condiciones de enseñanza en docencia y cultura escolar. Buenos Aires: Lugar Editorial, 2001.

KAPLÚN, G. Contenidos, itinerarios y juegos. Tres ejes para el análisis y la construcción de mensajes educativos. VI Congreso de ALAIC (Asociación Latinoamericana de Investigadores de la Comunicación). Santa Cruz de la Sierra, Bolivia, 2002.

KAPLÚN, G. Material Educativo: a experiência do aprendizado. Comunicação e Educação, São Paulo, v. 27, p. 46-60, maio/ago, 2003. Disponível em: http://www.revistas.usp.br/comueduc/article/view/37491. Acesso em: 07 out. 2020.

PAGÁN, J. B. Función didáctica de los materiales curriculares. Pixel Bit. Revista de Medios y Educación, v. 5, p. 29-46, 1995. Disponível em: https://recyt.fecyt.es/index.php/pixel/article/view/61077. Acesso em: 07 out. 2020.

RIZZATTI, I. M.; MENDONÇA, A. P.; MATTOS, F.; RÔÇAS, G.; SILVA, M. A. B. V.; CAVALCANTI, R. J. S.; OLIVEIRA, R. R. Os produtos e processos educacionais dos programas de pós-graduação profissionais: proposições de um grupo de colaboradores. Actio Docência em Ciências, v. 5, n.2, Curitiba, p. 1-17, ago. 2020.

SANTANA, M. La Enseñanza de las Matemáticas y las Nuevas Tecnologías de la Información y Comunicación. 2004. 854 f. Tese (Doutorado) - Curso de Pedagogia, Departamento de Pedagogía Facultad de Ciencias de La Educación y Psicología, Universitat Rovira I Virgili, Tarragona, 2004. Disponível em: https://www.tdx.cat/handle/10803/8927?show=full. Acesso em: 7 out. 2020. 
SANTOS GUERRA, M. A. Cómo evaluar los materiales. Cuadernos de Pedagogía, v. 194, p. 29-31, 1991. 